ORIGINAL

\title{
Evaluación química y organoléptica del ensilaje de maralfalfa (Pennisetum sp.) más yuca fresca (Manihot esculenta)
}

\section{Chemical and organoleptic evaluation of maralfalfa silage (Pennisetum sp.) plus fresh cassava (Manihot esculenta)}

\author{
Libardo Maza A, ${ }^{1}$ M.Sc, Oscar Vergara G, ${ }^{2 *}$ Ph.D, Elisa Paternina D, 1 , MVZ. \\ ${ }^{1}$ Universidad de Córdoba, Facultad de Medicina Veterinaria y Zootecnia, Semillero de Investigación \\ en Nutrición y Alimentación Animal "TALENTO", Montería, Colombia. 'Universidad de Córdoba, \\ Facultad de Medicina Veterinaria y Zootecnia, Grupo de Investigación en Reproducción Animal, \\ Montería, Colombia. *Correspondencia: overgara@sinu.unicordoba.edu.co
}

Recibido: Octubre de 2009; Aceptado: Diciembre de 2010.

\section{RESUMEN}

Objetivo. Evaluar la composición química y características organolépticas del ensilado de maralfalfa (Pennisetum sp.) más diferentes proporciones de yuca fresca (Manihot esculenta). Materiales y métodos. Se evaluaron 4 tratamientos $(T)$ de ensilaje de maralfalfa más diferentes proporciones de yuca fresca: 0\% (Tratamiento 1, Control), 5\% (Tratamiento 2), $10 \%$ (Tratamiento 3) y 15\% (Tratamiento 4). Se determinaron las proporciones de fibra detergente neutro (FDN), fibra detergente ácido (FDA), lignina, fracción de materia seca (MS), extracto etéreo (EE), cenizas y proteína bruta (PB). Además, se evaluaron las características organolépticas. Para evaluar las variables nutricionales del ensilaje, se utilizó un diseño completamente aleatorizado y los datos se analizaron a través de un análisis de varianza y la prueba de polinomios ortogonales. Para la evaluación del consumo y variables organolépticas se utilizaron 20 novillas, a las que se les ofreció $30 \mathrm{~kg}$ de ensilaje por cada tratamiento, analizando los resultados a través de estadística descriptiva. Resultados. Las variables nutricionales mostraron diferentes tipos de tendencias polinómicas. La MS y EE tuvieron comportamiento lineal, la lignina cuadrático y la PB, cenizas, FDN, FDA y pH comportamiento cúbico. Las características organolépticas para T3 y T4, fueron excelentes. El consumo promedio de T1, T2, T3 y T4 fue 4.66, 4.42, 4.58 y 4.74 kg, respectivamente. Conclusiones. La inclusión de raíz de yuca contribuyó favorablemente en la calidad nutricional del ensilaje de maralfalfa y sus características organolépticas.

Palabras clave: Calidad del producto, ensilaje, materia seca, proteína cruda, pruebas organolépticas, suplementos nutricionales. (Fuente: $C A B$ ). 


\section{ABSTRACT}

Objective. To evaluate the chemical composition and the organoleptic traits of maralfalfa silage (Pennisetum sp.), containing different proportions of fresh cassava (Manihot esculenta). Materials and methods. Four treatment $(T)$ groups of maralfalfa silage containing different percentage of fresh cassava were compared: $0 \%$ (Treatment 1 , Control), Treatment 5\% (Treatment 2), 10\% (Treatment 3), and 15\% (Treatment 4). Neutral detergent fiber (NDF), acid detergent fiber (ADF), lignin, fraction of dry matter $(D M)$, ether extract (EE), ash, and crude protein (CP) were analyzed by an analysis of variance and orthogonal polynomials. In addition, consumption and organoleptic traits were also analyzed using descriptive statistics, in 20 heifers, that received $30 \mathrm{~kg}$ of silage per treatment. Results. Nutritional variables showed different types of polynomial trends. $\mathrm{DM}$ and $\mathrm{EE}$ were linear trends, lignin was quadratic, and $\mathrm{CP}$, ash, NDF, ADF, and $\mathrm{pH}$ were cubic trends. Organoleptic traits for T3 and T4 were excellent. The average consumption for T1, T2, T3 and T4 was 4.66, 4.42, 4.58, and $4.74 \mathrm{~kg}$, respectively. Conclusions. The inclusion of fresh cassava root contributed positively in the nutritional quality of maralfalfa silage and organoleptic traits.

Key words: Crude protein, dry matter, nutritional supplements, organoleptic traits, product quality, silage making. (Source: $C A B$ ).

\section{INTRODUCCIÓN}

En el trópico bajo colombiano la principal fuente de alimento para el ganado son las pasturas, ya sean nativas o mejoradas, en las cuales la calidad y/o cantidad son características necesarias para llenar los requerimientos nutricionales de los animales. Sin embargo, estas dos propiedades son variables durante el año, ya que dependen de los períodos climáticos (seco y lluvioso) y de las características físico-químicas del suelo. Ante la escasez de forrajes que se presenta en la época seca, los pastos de corte se utilizan como alternativa alimenticia en la producción bovina, proporcionando un rendimiento por hectárea mayor. Recientemente se ha iniciado el uso del pasto maralfalfa (Pennisetum sp) como pasto de corte en la alimentación de ganado de leche, doble propósito y carne en el trópico, quizás por el interés que ha generado en los productores por su buena calidad y alta producción de biomasa, características importantes para ser ensilado (1-3). Sin embargo, varios son los estudios que muestran las imitaciones de este pasto, relacionados con su contenido nutricional y producción de forraje $(2,4-8)$.
Por otra parte, el ensilaje es el proceso mediante el cual se conserva forraje verde, preferiblemente de alta calidad y alto contenido de carbohidratos solubles, almacenándose en un lugar llamado silo. El proceso de conservación se realiza por medio de la fermentación láctica y su éxito radica en permitir una degradación dentro de límites cortos de tiempo que impidan bruscas transformaciones en la composición del producto que se va a conservar $(9,10)$.

La calidad del ensilaje depende principalmente del grado de compactación y la cantidad de oxígeno que ha quedado en el material ensilado. Sin embargo, los niveles de materia seca y carbohidratos solubles son determinantes en la fermentabilidad de un ensilaje $(11,12)$, por lo que la inclusión de un mayor contenido de carbohidratos solubles, facilita la capacidad de fermentación y degradación de otros sustratos, por estimular el crecimiento de bacterias ácido lácticas (7).

De acuerdo a lo anterior, se consideró de gran importancia realizar un estudio, en el cual se evaluó ensilaje de maralfalfa, al que se le adicionó diferentes proporciones de yuca fresca, para mejorar sus 
características fermentativas (13), como alternativa de alimentación bovina bajo las condiciones del trópico bajo colombiano. El objetivo de esta investigación fue evaluar la composición química y organoléptica del ensilaje de maralfalfa (Pennisetum sp.) más yuca fresca (Manihot esculenta) con el fin de proporcionarle a los productores información sobre el ensilaje de este pasto.

\section{MATERIALES Y MÉTODOS}

Sitio de estudio. El estudio se realizó en la hacienda Pamplona, en el municipio Planeta Rica, Córdoba. Esta zona pertenece a la clasificación de bosque seco tropical (14), presenta una temperatura promedio de $28^{\circ} \mathrm{C}$, precipitación promedio anual de $1850 \mathrm{~mm}$ y a una altura de 180 m.s.n.m. La maralfalfa utilizada para hacer el ensilaje se cosechó de un cultivo de 1.5 hectáreas, con 60 días de rebrote. La yuca se obtuvo de un cultivo de 2 hectáreas, con una edad de 8 meses, cosechando la raíz de la planta para adicionarla al ensilaje.

Diseño experimental. Los tratamientos de los ensilajes evaluados fueron: $\mathrm{T} 0=100 \%$ pasto maralfalfa; $\mathrm{T} 1=95 \%$ pasto maralfalfa $+5 \%$ de yuca fresca; T2=90\% pasto maralfalfa $+10 \%$ de yuca fresca; y T3 $=85 \%$ pasto maralfalfa $+15 \%$ de yuca fresca. Para cada tratamiento se utilizaron tres repeticiones, las cuales estaban constituidas por ensilajes depositados en tanques herméticos con capacidad de 40 litros que fueron distribuidos aleatoriamente en un sitio destinado para tal fin. El ensilaje fue compactado manualmente y se mantuvo en condiciones anaeróbicas por 21 días (10). Luego de destapado, se tomó una muestra de $500 \mathrm{~g}$ mezclando porciones de la parte inferior, media y superior de cada tanque por cada tratamiento y llevadas al laboratorio.

Análisis de laboratorio. A las muestras se les determinó materia seca, por medio de deshidratación a $105^{\circ} \mathrm{C}$ por secado directo en una estufa al vacío, en el laboratorio de nutrición y alimentación animal de la Universidad de Córdoba.
En el laboratorio de bromatología de la Universidad Nacional, Sede Medellín, se realizaron los análisis de FDN, FDA y lignina por medio del método descrito por Van Soest y Wine (15). En los laboratorios de PREMEX (Medellín) fueron evaluados los contenidos de nitrógeno por medio del método de micro Kjeldahl (16). Las proporciones de extracto etéreo se evaluaron por el método de Soxhlet y cenizas por medio del método de residuo mineral fijo descritos por la AOAC (17).

Evaluación de las características organolépticas. Se evaluaron al momento de destapar los ensilados, teniendo en cuenta la tabla de evaluación de ensilajes propuesta por Chaverrra y Bernal (18) (Tabla 1).

Tabla 1. Características organolépticas para la evaluación de la calidad de ensilajes.

\begin{tabular}{|c|c|c|c|c|}
\hline INDICADOR & EXCELENTE & BUENA & REGULAR & MALA \\
\hline COLOR & $\begin{array}{l}\text { Verde } \\
\text { aceituna } \\
\text { o amarillo } \\
\text { oscuro }\end{array}$ & $\begin{array}{l}\text { Verde } \\
\text { amarillento. } \\
\text { Tallos con } \\
\text { tonalidad } \\
\text { mas pálida } \\
\text { que las } \\
\text { hojas }\end{array}$ & $\begin{array}{l}\text { Verde } \\
\text { oscuro }\end{array}$ & $\begin{array}{l}\text { Marrón } \\
\text { oscuro, casi } \\
\text { negro o } \\
\text { negro. }\end{array}$ \\
\hline OLOR & $\begin{array}{l}\text { A miel o } \\
\text { azucarado } \\
\text { de fruta } \\
\text { madura }\end{array}$ & $\begin{array}{l}\text { Agradable, } \\
\text { con ligero } \\
\text { olor a } \\
\text { vinagre }\end{array}$ & $\begin{array}{l}\text { Fuerte, } \\
\text { Ácido olor } \\
\text { a vinagre, } \\
\text { (ácido } \\
\text { butírico) }\end{array}$ & $\begin{array}{l}\text { Desagradable, } \\
\text { a mantequilla } \\
\text { rancia. }\end{array}$ \\
\hline TEXTURA & $\begin{array}{l}\text { Conserva } \\
\text { sus } \\
\text { contornos } \\
\text { continuos }\end{array}$ & $\begin{array}{l}\text { Igual al } \\
\text { anterior }\end{array}$ & $\begin{array}{l}\text { Se separan } \\
\text { las hojas } \\
\text { fácilmente } \\
\text { de los tallos } \\
\text { tienden a } \\
\text { ser transpa- } \\
\text { rentes y los } \\
\text { vasos ve- } \\
\text { nosos muy } \\
\text { amarillos. }\end{array}$ & $\begin{array}{l}\text { No se observa } \\
\text { diferencia } \\
\text { entre tallos } \\
\text { y hojas. Es } \\
\text { más amorfa } \\
\text { y jabonosa. } \\
\text { Al tacto es } \\
\text { húmeda y } \\
\text { brillante. }\end{array}$ \\
\hline
\end{tabular}

Prueba de consumo. Para realizar la prueba de consumo, se escogieron aleatoriamente 20 novillas de la raza Brahman con edades de 20 a 24 meses, con un peso vivo promedio de $280 \mathrm{~kg}$. Estos animales fueron distribuidos aleatoriamente en los tratamientos (5 por tratamiento). A cada grupo se le ofreció en horas de la mañana $30 \mathrm{~kg}$ ensilaje en una única ración por un lapso de 60 minutos. Antes del suministro del ensilaje, los animales se encontraban pastoreando en praderas de Brachiaria decumbens. El pesaje del ensilaje se realizó en una báscula colgante de reloj cada 15 minutos, por cada tratamiento evaluado, hasta terminado el lapso de tiempo. 
Análisis estadístico. Para el análisis de las características nutricionales se realizó un análisis de varianza, a través del procedimiento GLM del paquete estadístico SAS 9.0 (19), para determinar si existía o no diferencia estadística entre los tratamientos. Además, se realizó la prueba de polinomios ortogonales para determinar la tendencia de las variables nutricionales, de acuerdo con el porcentaje de yuca fresca adicionado al ensilaje. Las características organolépticas y consumo se evaluaron por medio de estadística descriptiva.

\section{RESULTADOS}

Se observó una tendencia lineal $(p<0.05)$ de la MS de acuerdo con los niveles de inclusión de yuca fresca (Figura 1), aumentando la MS a medida que aumentó el porcentaje de yuca fresca.

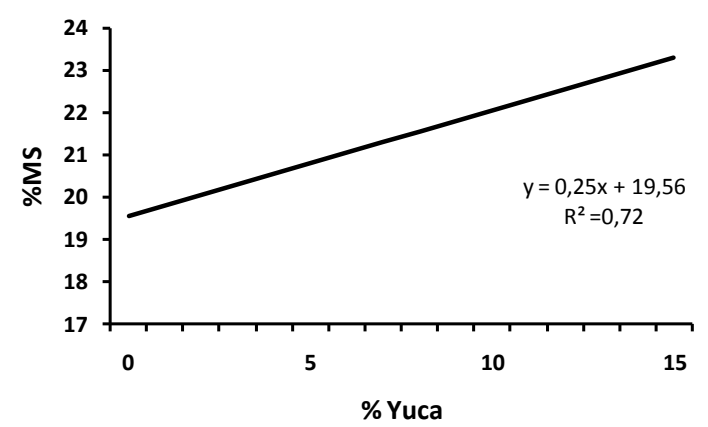

Figura 1. Regresión lineal del porcentaje de MS según el porcentaje de yuca fresca.

La tendencia de la PB según la inclusión de yuca fresca en el ensilaje fue cúbica $(p<0.01)$. En la figura 2, se puede apreciar que el pico de PB se alcanza en T1, disminuye hacia T2 y tiende a aumentar en T3.

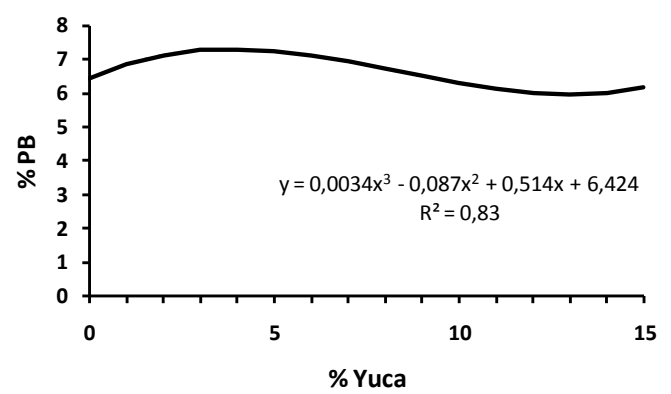

Figura 2. Regresión cúbica del porcentaje de PB de acuerdo con el porcentaje de yuca fresca.
Para EE se encontró respuesta lineal $(p<0.05)$, observándose una disminución de éste a medida que aumentaba la inclusión de yuca fresca al ensilaje (Figura 3 ).

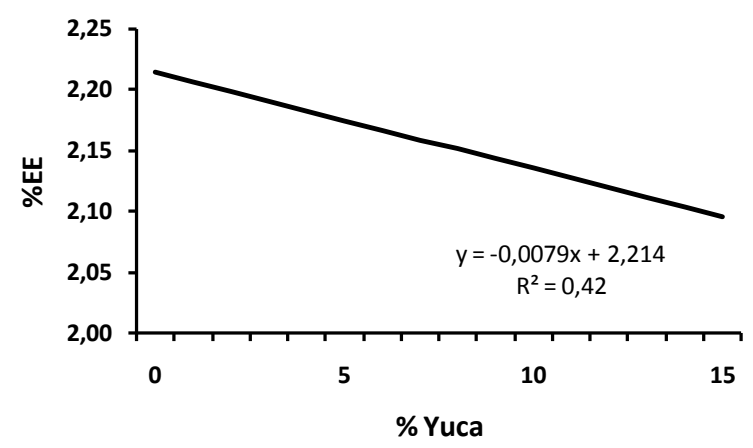

Figura 3. Regresión lineal del porcentaje de EE de acuerdo con el porcentaje de yuca fresca

En lo que respecta a las cenizas, estas tuvieron un comportamiento cúbico $(p<0.001)$, según el porcentaje de yuca adicionado al ensilaje (Figura 4). Se puede notar que las concentraciones de cenizas tienden a ser similares en T0, T1 y T2 y tiende a aumentar en T3.

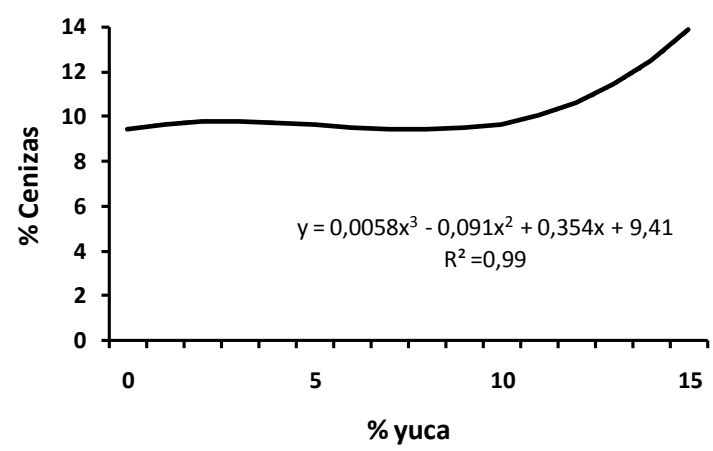

Figura 4. Regresión cúbica del porcentaje de cenizas según el porcentaje de yuca fresca

La figura 5 muestra la tendencia cúbica de FDN $(p<0.001)$, según los niveles de inclusión de yuca fresca al ensilaje. Se puede notar que la mayor concentración de FDN se presentó en T0, disminuyendo hacia T1 y T2 y tendió a aumentar en T3. Las concentraciones de FDA presentaron tendencia similar que FDN $(p<0.001)$. 


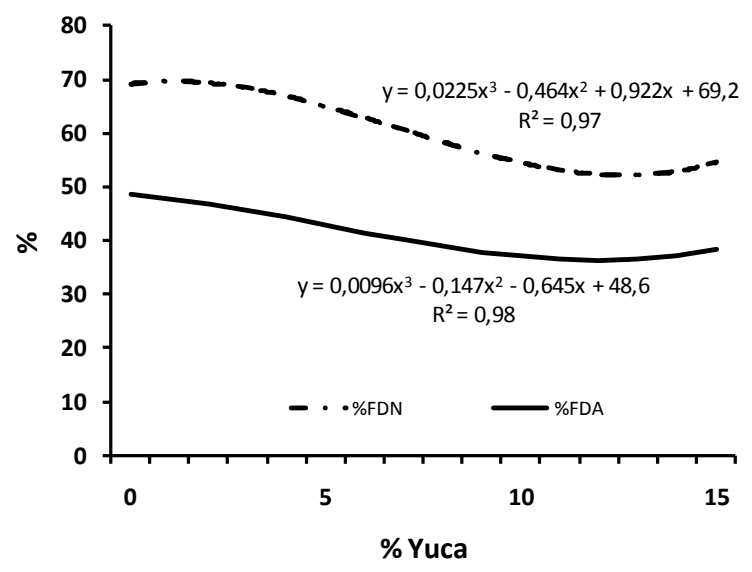

Figura 5. Regresión cúbica de FDN y FDA según el porcentaje de yuca fresca

Para la lignina se encontró tendencia cuadrática $(p<0.001)$ y mostró una disminución a medida que los niveles de inclusión de yuca aumentaron a 5, 10 y 15\% (Figura 6).

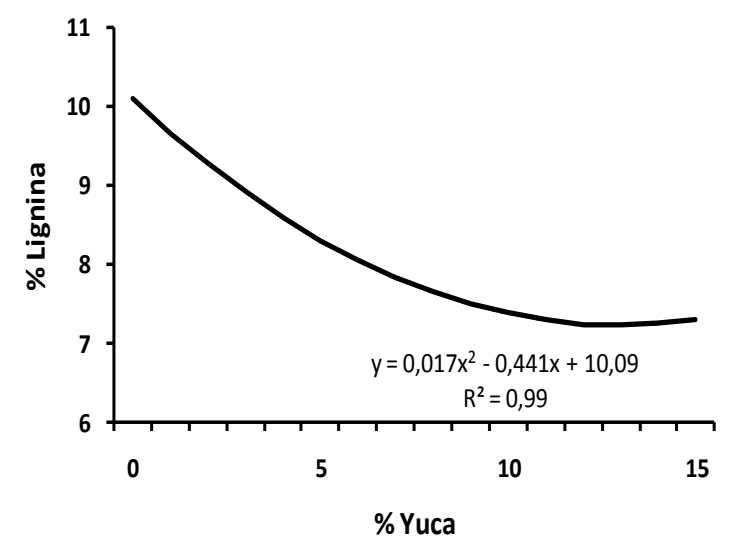

Figura 6. Regresión cuadrática del porcentaje de lignina según el porcentaje de yuca fresca

El pH tuvo tendencia cúbica $(p<0.001)$ y mostró un aumento de T0 a T1, luego disminuyó en T2 (pero a niveles mayores que en T0) y posteriormente aumentó en T3 (Figura 7).

Los resultados obtenidos en este estudio, mostraron para las características organolépticas un mejor comportamiento

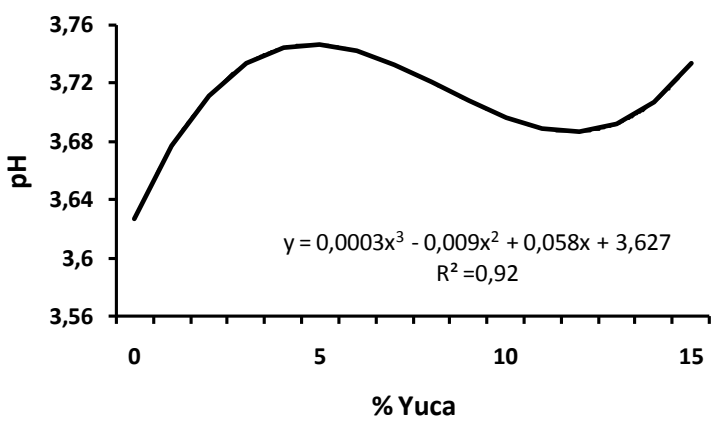

Figura 7. Regresión cúbica del pH según el porcentaje de yuca fresca

para el tratamiento en que se adicionó $15 \%$ de yuca, en el cual las características fueron excelentes. La figura 8 muestra las características organolépticas evaluadas en cada tratamiento.

Respecto al color, los tratamientos experimentales presentaron una cualificación excelente (tonalidad verde aceituna), mejor que los del tratamiento testigo (tonalidad verde amarillento). En cuanto al olor, T2 y T3 presentaron un olor excelente, similar al de fruta madura, característico de ensilajes de excelente calidad, superior al encontrado en TO y T1. La textura tuvo un comportamiento bueno para T0, T1 y T2, mientras que para T3 fue excelente. En ninguno de los tratamientos se observó degradación del material ensilado, mostrando un buen nivel de conservación para todos los tratamientos. De acuerdo a lo anterior, se puede notar (Figura 8) que el aumento de los niveles de inclusión de yuca, mejoró significativamente las características organolépticas del ensilaje.

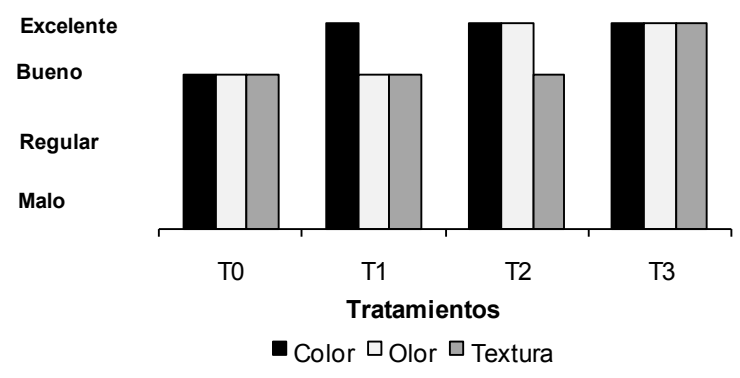

Figura 8. Características organolépticas para los diferentes tratamientos. 
En la tabla 2 se observan los diferentes consumos promedios cada 15 minutos, mostrando homogeneidad entre las cantidades consumidas de cada tratamiento.

Tabla 2. Consumo acumulado de ensilaje ( $\mathrm{kg}$ de materia seca) cada 15 minutos para cada tratamiento.

\begin{tabular}{ccccc}
\hline Tratamiento & \multicolumn{4}{c}{ Tiempo (min) } \\
& $\mathbf{1 5}$ & $\mathbf{3 0}$ & $\mathbf{4 5}$ & $\mathbf{6 0}$ \\
\hline $\mathrm{T}_{0}$ & 2.30 & 2.78 & 3.84 & 4.66 \\
$\mathrm{~T}_{1}$ & 2.46 & 3.12 & 3.74 & 4.42 \\
$\mathrm{~T}_{2}$ & 2.38 & 2.98 & 3.86 & 4.58 \\
$\mathrm{~T}_{3}$ & 2.56 & 3.34 & 3.70 & 4.74 \\
\hline
\end{tabular}

$T_{0}: 100$ ensilaje de maralfalfa; $T_{1}: 95 \%$ ensilaje de maralfalfa más $5 \%$ yuca fresca; $T_{2}: 90 \%$ ensilaje de maralfalfa más $10 \%$ yuca fresca; $\mathrm{T}_{3}: 85 \%$ ensilaje de maralfalfa más $15 \%$ yuca fresca

Se puede notar que durante los primeros 15 minutos se dio un consumo rápido, obteniendo una aceptabilidad inmediata de todos los tratamientos por parte de los animales. Posteriormente, el consumo se mantuvo con un crecimiento paulatino hasta lograr un consumo promedio por animal máximo de 4.66 (T0), 4.42 (T1), 4.58 (T2) y 4.74 (T3). En la figura 9 , se muestra el comportamiento del consumo promedio acumulado de ensilaje, por parte los animales a través del tiempo.

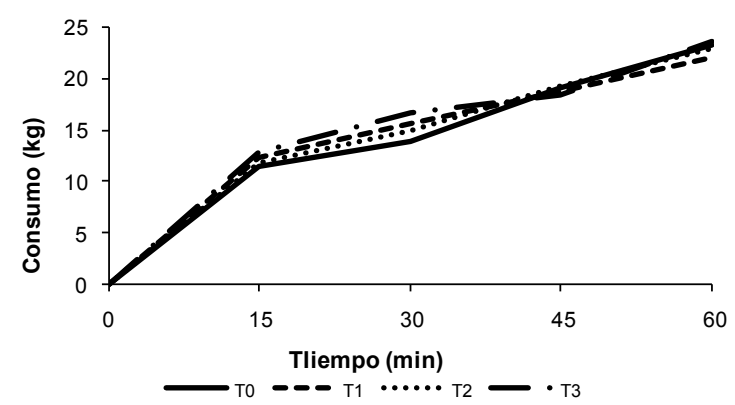

Figura 9. Cantidad de ensilaje consumido en el tiempo (60 min) para cada tratamiento.

\section{DISCUSIÓN}

Las concentraciones de MS no fueron óptimas en ninguno de los tratamientos (12), obteniéndose un máximo de materia seca en T3 $(23.01 \%)$ con un
$15 \%$ de inclusión de yuca y un mínimo para T0 $(19.05 \%)$, sin inclusión de yuca. Los resultados de MS son menores a los encontrados por Acosta (5), Eichelberger (20) y Lara (21) en ensilajes de maíz y mixtos de maíz más leguminosas; efecto que es atribuido a que el pasto maralfalfa posee una concentración de materia seca muy baja ( $24 \%$ a los 60 días de rebrote). Contenidos de MS inferiores al 30\%, puede originar problemas de contaminación e incremento de las pérdidas del ensilaje, porque se favorece la actividad bacteriana (especialmente Clostridium) y aumenta la producción de ácido butírico (12).

La tendencia a disminuir los niveles de PB al aumentar la inclusión de yuca fresca al ensilaje, puede ser originado por la baja concentración de proteína presente en la raíz de yuca fresca (22). Las concentraciones de proteína halladas fueron superiores a los reportados en ensilaje de maralfalfa más caña de azucar (7) y similares a las encontradas en ensilaje de pasto elefante (Pennisetum purpureum) más harina de yuca (23), por lo que se puede afirmar que los pastos Pennisetum y la yuca proporcionan mayor cantidad de proteina al ensilaje, además del contenido de azucares.

La concentración de EE en los diferentes niveles de inclusión de yuca fresca permitiría una adecuada digestibilidad de la fibra, ya que contenidos elevados de lípidos en la dieta de los rumiantes podría ocasionar envolvimiento físico de la fibra (mayor al $7 \%$ ), dificultando el ataque microbiano, y por lo tanto reduciendo la digestibilidad del ensilaje $(24,25)$. El contenido de EE en las diferentes inclusiones de yuca fresca al ensilaje fue inferior al encontrado en ensilaje de maralfalfa más caña de azucar (7) y similar al reportado en ensilaje de pasto elefante (Pennisetum purpureum) más harina de yuca (13).

Las concentraciones de cenizas halladas en este estudio, son mayores a las encontradas por Acosta (5), Eichelberger (20) y Lara (21) en ensilajes de maíz y mixtos de maíz más leguminosas y muy cercanas a las reportadas por Lara (21) en ensilajes de 
leguminosas. Estas altas concentraciones pueden ser atribuidas a que el pasto maralfalfa posee concentraciones altas de cenizas (2), sumado probablemente a la presencia de trazas en la raíz de yuca, provenientes del suelo, que al no realizar un lavado previo del material mantuvo partículas de suelo, el cual es altamente rico en minerales, pudiendo esto causar probablemente un mayor efecto en T3.

La tendencia a disminuir la FDN en el ensilaje a medida que se aumenta la inclusión de yuca fresca, está muy asociada al poco aporte de fibra que hace la raíz de yuca al ensilado (26). Sin embargo, los niveles fueron superiores a los encontrados por Acosta (5) y Blanco et al (27) en ensilajes de maíz sorgo y trigo y avena, sauco y acacia, respectivamente, quizás porque las condiciones ambientales donde se realizaron estas investigaciones son muy diferentes a las de este estudio y las gramíneas en condiciones de trópico alto son plantas C3, las cuales poseen niveles de fibra menores y un menor aporte de fibra por parte de los granos en las plantas de maíz. Los T2 y T3 mostraron menor porcentaje de FDN, con respecto a los reportados por Eichelberger (20) y Oliveira et al (28) en ensilaje de maíz, lo cual es atribuido a la mayor concentración de raíz de yuca y por ende un menor a porte de FDN (22).

Al igual que la FDN, la FDA mostró una disminución gradual a medida que se aumentaron los niveles de yuca en los tratamientos; efecto producido por los niveles bajos de fibra contenidos en la raíz de yuca (22). No obstante, estos niveles siguen siendo más altos que los reportados por Acosta (5) y Blanco et al (27) en ensilajes de maíz y gramíneas con leguminosas, respectivamente; efecto que de igual manera, es atribuido a un menor aporte de fibra por parte de los granos encontrados en este tipo de especies.

La disminución de lignina en el ensilaje, puede ser causada porque los niveles de fibra y lignina en la raíz de yuca son muy bajos (26), contribuyendo favorablemente con la calidad del ensilaje, volviéndolo más digestible en el rumen. Sin embargo, estos resultados son mayores a los encontrados por Eichelberger (20) en ensilajes de maíz, maíz más soya y maíz más fríjol (4.77, 4.85 y $5.54 \%$, respectivamente) y Oliveira et al (28) en ensilaje de maíz (5.9\%). Efecto que puede ser atribuido a que la planta de maíz para ser conservada por medio del proceso de ensilaje, debe estar a una edad no mayor de 70 días, en el cual los niveles de lignificación de la planta son mínimos y el estado de los granos de la planta se hallan entre lechoso y semiduro. Por otra parte, las especies leguminosas son plantas tipo C3, los cuales poseen una pared celular mucho más delgada y mayor contenido celular que las plantas tipo C4, al cual pertenece el pasto maralfalfa.

Las condiciones del material a ensilar en todos los tratamientos, especialmente la concentración de carbohidratos, fueron adecuadas para que el $\mathrm{pH}$ disminuyera a un nivel adecuado para la preservación del ensilaje (29). De acuerdo a resultados encontrados por Pires et al (13), en ensilajes de pasto elefante (Pennisetum purpureum) y pasto elefante más harina de yuca, reportaron que en este tipo de ensilajes el ácido láctico posee un mayor poder de acidificación en comparación con los ácidos acético y butírico, lo que ayuda a la conservación del ensilaje.

La excelente calidad del ensilaje, de acuerdo a las características organolépticas, puede se debido a un aporte significativo de la raíz de yuca en cuanto a carbohidratos solubles y materia seca, lo cual concuerda con lo informado por Schroeder (10) y Cisneros et al (11), quienes afirman que los niveles de materia seca y carbohidratos solubles son determinantes en la fermentabilidad del ensilaje.

El color excelente del ensilaje en los tratamientos a los cuales se les adicionó yuca fresca, puede ser atribuido a la mayor concentración de carbohidratos solubles en la yuca, que permitió una mayor ensilabilidad y conservación del ensilaje. Al igual, que los valores bajos de $\mathrm{pH}$, que oscilaron entre 3.63 y 3.75 en los diferentes tratamientos, lo cual evitó el crecimiento 
de bacterias saprofitas. En relación al olor y textura, no se apreciaron olores desagradables ni degradación del material, quizás por el mismo efecto de valores de $\mathrm{pH}$ bajos, mencionado anteriormente.

Respecto al comportamiento ingestivo en la prueba de consumo de ensilaje, no se observó una tendencia marcada de los animales a consumir un tratamiento específico, lo que sugiere que la aceptabilidad de los diferentes ensilajes por parte de los animales fue similar, por lo tanto, la diferencia entre los tratamientos estaría determinada principalmente por el contenido nutricional y las variables organolépticas, más que por la gustosidad del ensilaje.

Como conclusión, se puede afirmar que la inclusión de yuca al 15\% mejora la calidad del ensilaje de maralfalfa, principalmente por el contenido de PB aceptable, reducción en los contenidos de FDA, FDN y lignina y un $\mathrm{pH}$ adecuado para la fermentación y conservación. Además de presentar excelentes características organolépticas y mayor aceptabilidad por parte de los animales. Para incrementar los niveles de proteína suministrado a los animales a través de los diferentes ensilajes evaluados, se puede adicionar nitrógeno no proteico al momento de la oferta.

\section{Agradecimientos}

A los Medicos Veterinarios Zootecnistas Amilkar Causil Vergara y Alejandro Reza Cordero y al Laboratorio de Nutrición Animal de la Universidad de Córdoba por facilitar los medios para la realización de esta investigación.

\section{REFERENCIAS}

1. Ramírez $Y$, Pérez J. Efecto de la edad de corte sobre el rendimiento y composición química delo pasto maralfalfa (Pennisetum sp.). Rev Unell Cienc Tec 2006; 24:57-62.

2. Correa HJ, Arroyave $\mathrm{H}$, Henao J, Lopez A, Cerón JM. Pasto maralfalfa: Mitos y realidades. 2006 (fecha de acceso: febrero 16 del 2009). URL disponible en: http://www.agro.unalmed.edu. co/departamentos/panimal/docs/ Maralfalfa.pdf.

3. Clavero T, Razz R. Valor nutritivo del pasto maralfalfa (Pennisetum purpureum $x$ Pennisetum glaucum) en condiciones de defoliación. Rev Fac Agron (LUZ) 2009; 26:78-87.

4. Carulla J, Cárdenas E, Sánchez N, Riveros C. Valor nutricional de los forrajes más usados en los sistemas de producción lechera especializada de la zona andina colombiana. En: Memorias V Seminario en reproducción y matabolismo en bovinos. Universidad de Caldas, Manizales; 2004.
5. Acosta YM. Comparación de ensilajes de grano húmedo de maíz sorgo y trigo para la producción de leche. 2006 (fecha de acceso: febrero 16 de 2009). URL disponible en: http:// www.produccion-animal.com.ar/ produccion_y_manejo_reservas/ reservas_silos/89-comparacion.pdf.

6. Blair C. Evaluación económica de alternativas de bajo costo para la suplementación de ganado en época seca. Trabajo de grado. Ingeniería Agronómica, Universidad Earth, Guácimo, Costa Rica 2007. (fecha de acceso: febrero 16 de 2009). URL disponible en: http://usi.earth.ac.cr/ glas/sp/dpg/52-2007.pdf.

7. Posada $S$, Rosero $R$, Jiménez $A$. Valor nutricional y características de fermentación del ensilaje de pasto maralfalfa (Pennisetum sp.) con diferentes niveles de inclusión de caña de azúcar (Saccharum officinarum). Rev Col Cienc Pec 2007; 20(4):640. 
8. Márquez $F$, Sánchez J, Urbano D, Dávila C. Evaluación de la frecuencia de corte y tipos de fertilización sobre tres genotipos de pasto elefante (Pennisetum purpureum). 1. Rendimiento y contenido de proteína. Zootec Trop 2007; 25(4):253-259.

9. Bernal E. Pastos y forrajes tropicales. Producción y manejo. 2a Ed. Bogotá DC, Colombia: Banco Ganadero; 1991.

10. Schroeder JW. Silage Fermentation and preservation. North Dakota State University, North Dakota, USA 2004. (fecha de acceso: febrero 15 de 2009). URL disponible en: http:// www.ag.ndsu.edu/pubs/ansci/dairy/ as1254w.htm.

11. Cisneros M, Romero O, Castillo E, Penedo J. La conservación de alimento para el ganado. [Monografía]. Cuernavaca, México: Universidad Autónoma del Estado de Morelos, Facultad de Ciencias Agropecuarias; 1994.

12. Ashbell G, Weinberg ZG. Silage from tropical cereals and forage crop. En: FAO Electronic conference on tropical silage. 1999. (fecha de acceso: febrero 16 de 2009). URL disponible en: http://www.fao.org/docrep/005/ x8486e/x8486e0q.htm.

13. Pires AJV, Carvalho GGP, Garcia $R$, Junior JNC, Ribeiro LSO, Chagas DMT. Capim-elefante ensilado com casca de café, farelo de cacau ou farelo de mandioca. Rev Soc Bras Zootec 2009; 38:34-39.

14. Holdridge L. Ecología basada en zonas de vida. Quinta reimpresión. San José, Costa Rica: Editorial IICA; 2000.

15. Van Soest PJ, Wine RH. Use of detergents in the analysis of fibrous feed. IV. Determination of plant cell wall constituents. J Assn Oficial Agric Chem 1967; 50:50-55.
16. Nielsen SS. Introduction to the Chemical Analysis of Foods. Boston, USA: Jones and Bartlett; 1994.

17. A.O.A.C - Association of Official Agricultural Chemists. Oficial methods of analysis. 15th ed. Washington DC, USA; 1990.

18. Chaverra H, Bernal J. El ensilaje en la alimentación del ganado vacuno. Bogotá DC, Colombia: IICA, Tercer Mundo Editores; 2000.

19. SAS OnlineDoc 9.1.3. Cary, USA: SAS Institute Inc; 2007.

20. Eichelberger L, Siewerdt L, Silveira PJ. Efeitos da inclusao de soja ou feijao miúdo e uso de inoculante na qualidade da silaben de milho. Rev Soc Bras Zootec 1997; 4:667-674.

21. Lara S. Evaluación agronómica y nutricional de monocultivos y cultivos asociados de maíz y leguminosas para la producción de forraje fresco y ensilado. [Trabajo de grado]. Montería, Colombia: Universidad de Córdoba, Facultad de Medicina Veterinaria y Zootecnia, Departamento de Ciencias Pecuarias; 2002.

22. Buitrago J, Gil J, Ospina B. La yuca en la alimentación avícola. Cuadernos Avícolas No 14. Federación Nacional de Avicultores de Colombia - Fondo Nacional Avícola (FENAVI - FONAV). 2001 (fecha de acceso: febrero 16 del 2009). URL disponible en: http:// www.clayuca.org/PDF/alimentacion_ avicola.pdf.

23. Pinho, BD, Pires AJV, Ribeiro LSO, Carvalho GGP. Ensilagem de capimelefante com farelo de mandioca. Rev Bras Saúde Prod Ani 2008; 9:641-651. 
24. Evangelista AR, De Lima JA. Utilização de silagem de girassol na alimentação animal. En: Simpósio sobre produção e utilização de forragens conservadas, Maringá, Brasil 2001 (fecha de acceso: febrero 15 del 2011); 177-217. URL disponible en: http://www.nupel. uem.br/girassol.pdf.

25. Gallardo M. Soja: harinas de extracción para la alimentación del ganado. Un análisis de las cualidades nutricionales de los diferentes tipos, de acuerdo al método de extracción utilizado. Instituto Nacional de Tecnología Agropecuario - INTA. Rafaela, Argentina. 2005 (fecha de acceso: febrero 15 de 2009). URL disponible en: http://www.inta.gov.ar/rafaela/ info/documentos/art_divulgacion/ ad_0015.htm.

26. Gil J, Buitrago A. La yuca en la alimentación animal. En: La yuca en el tercer milenio. Sistemas modernos de producción, procesamientos, utilización y comercialización. Publicaciones CIAT. Cali, Colombia 2002 (fecha de acceso: marzo 3 del 2009); p. 527 - 569. URL disponible en: http://www.clayuca.org/PDF/ libro_yuca/capitulo28.pdf.
27. Blanco GM, Chamorro DR, Arreaza LC, Rey AM. Evaluación nutricional del ensilaje de Sambucus peruviana, Acacia decurrens y Avena sativa. Rev Corpoica 2005 (fecha de acceso: marzo 3 del 2009); 6: 81-85. URL disponible en: http://www.corpoica. org.co/SitioWeb/Archivos/Revista/9_ EvaluaNutricional_81-85_v6n2.PDF.

28. Oliveira LB, Pires AJV, Carvalho GGP, Ribeiro5 LSO, Almeida VV, Peixoto CAM. Perdas e valor nutritivo de silagens de milho, sorgo-sudão, sorgo forrageiro e girasol. Rev Soc Bras Zootec 2010; 39:61-67.

29. Ojeda GF, Caceres GO, Esperance M.Conservación de forrajes. La habana Cuba: Pueblo y Educación; 1991. 